\title{
Diagnosis of Peripheral Lung Lesions by EBUS-Guided TBB in Routine Practice
}

\author{
Diagnostik peripherer pulmonaler Läsionen mittels EBUS-geführter \\ transbronchialer Biopsie (TBB) in der täglichen Praxis
}

Authors

Institutions
U. Ostendorf', A. Scherff' , B. Khanavkar'1, S. Ewig' ${ }^{1}$ E. Hecker ${ }^{2}$

${ }^{1}$ Thoraxzentrum Ruhrgebiet, Kliniken für Pneumologie und Infektiologie, Evangelisches Krankenhaus Herne und Augusta-Kranken-Anstalt Bochum, Germany

2 Thoraxzentrum Ruhrgebiet, Klinik für Thoraxchirurgie, Evangelisches Krankenhaus Herne, Germany received 15. 10.2011

accepted 18.10. 2011

Bibliography

Dol http://dx.doi.org/

10.1055/s-0031-1291471

Pneumologie 2011; 65: 730-735

(c) Georg Thieme Verlag KG

Stuttgart · New York

ISSN 0934-8387

Correspondending author

Prof. Dr. med. Santiago Ewig Thoraxzentrum Ruhrgebiet

Kliniken für Pneumologie und Infektiologie

Evangelisches Krankenhaus

Herne und Augusta-Kranken-

Anstalt Bochum

Bergstrasse 26

44791 Bochum

ostendorf@augusta-bochum.de

\section{Abstract \\ $\nabla$}

Objective: To determine the diagnostic yield of EBUS guided TBB performed in routine practice with flexible bronchoscopy and under moderate sedation in ambulatory and hospitalized patients. Methods: Bronchoscopy was performed under standard conditions in ambulatory and hospitalised patients. Bronchoscopically invisible peripheral pulmonary lesions were located with 20 MHZ-EBUS-probe and transbronchial biopsy was taken using a guiding sheath. Fluoroscopy was additionally performed as required to identify the lesion.

Results: 257 patients with peripheral pulmonal lesions were investigated, with malignancy in $70 \%$ of those with a diagnosis established. 175/ $257(68.1 \%)$ of lesions were detected with EBUS. In 139/176 (79.4\%) of these lesions, TBB enabled a final diagnosis. The TBB yield depended on lesion size. It was $61.3 \%$ in lesions $\leq 20 \mathrm{~mm}, 85.5 \%$ $>20 \mathrm{~mm} / \leq 30 \mathrm{~mm}$, and $81.2 \%$ in $\geq 30 \mathrm{~mm}(\mathrm{p}<$ 0.0001 ). This yield was also affected by the position of the probe (centrally $84.5 \%$, tangentially $57.6 \%, p=0.01)$ ). Operator experience did not influence the diagnostic yield but considerably shortened investigation time $(4.9 \pm 3.5$ vs. $6.2 \pm$ $4.2 \mathrm{~min}, \mathrm{p}=0.042$ ). Relevant complications occurred in only $1.9 \%$ ( 3 cases of postinterventional pneumothorax).

Conclusions: In an unselected population, EBUSguided TBB has a high diagnostic yield in peripheral lesions $>20 \mathrm{~mm}$ whereas its yield decreases considerably in smaller lesions. Complications are very rare. EBUS-guided TBB can successfully and safely be performed by flexible bronchoscopy.

\section{Zusammenfassung \\ $\nabla$}

Fragestellung: Diese Arbeit untersucht die diagnostische Ausbeute der EBUS-orientierten transbronchialen Biopsie (TBB) mittels flexibler Bronchoskopie unter Routinebedingungen bei ambulanten und stationären Patienten.

Methoden: Die Bronchoskopie wurde unter Standardbedingungen bei ambulanten und stationären Patienten durchgeführt. Bronchoskopisch nicht sichtbare periphere pulmonale Herde wurden mittels der 20-MHZ-EBUS-Sonde aufgesucht, die transbronchiale Biopsie erfolgte unter Nutzung eines Führungskatheters. Bedarfsweise wurde zusätzlich eine Durchleuchtung zur Identifikation der Lage des Herdes durchgeführt.

Ergebnisse: Insgesamt wurden 257 Patienten mit peripheren pulmonalen Rundherden untersucht, davon erwiesen sich $70 \%$ als maligne. 175/257 $(68,1 \%)$ der Herde wurden mittels EBUS lokalisiert. In 139/176 (79,4\%) wurden diese Herde mittels TBB histologisch diagnostiziert. Die Ausbeute der TBB war abhängig von der Herdgröße: sie betrug $61,3 \%$ in Herden von einer Größe $\leq 20$ $\mathrm{mm}, 85,5 \%$ bei $>20 / \leq 30 \mathrm{~mm}$ und $81,2 \%$ bei Herdgrößen $\geq 30 \mathrm{~mm}(\mathrm{p}<0.0001)$. Die Ausbeute hing zusätzlich ab von der Lage der Herde (zentral $84,5 \%$, peripher 57,6\%, p=0.01). Die Erfahrung des Untersuchers hatte keinen Einfluss auf die Ausbeute, wohl aber ging eine größere Erfahrung mit kürzeren Untersuchungszeiten einher (4,9 $\pm 3,5$ vs. $6,2 \pm 4,2 \mathrm{~min}, \mathrm{p}=0,042$ ). Relevante Komplikationen traten nur in 1,9\% der Fälle auf (3 Fälle eines Pneumothorax).

Schlussfolgerungen: In einer unselektierten Population hat die EBUS-orientierte TBB eine hohe diagnostische Ausbeute bei peripheren Herden $>20 \mathrm{~mm}$. Die Ausbeute sinkt deutlich bei kleineren Herden. Komplikationen waren sehr selten. Die EBUS-geleitete TBB kann erfolgreich und sicher auch mit flexibler Bronchoskopie durchgeführt werden. 


\section{Introduction}

\section{$\nabla$}

EBUS-guided TBB is an established procedure to diagnose bronchoscopically invisible, peripheral pulmonary lesions for more than 10 years.

Nevertheless, available data are quite heterogeneous and poorly comparable. Obviously, the diagnostic success depends on the size of pulmonary lesion. However, there are remarkable differences in diagnostic yield especially in small lesions $<20 \mathrm{~mm}$. While some studies describe high diagnostic yields of about $60-80 \%$ independent of lesion-size [ $1-8]$, other authors report a dramatical decrease in diagnostic yield in lesions $<20 \mathrm{~mm}$ [911]. Furthermore, the procedures used in different trials vary widely. In some studies, bronchoscopy is performed in general anaesthesia $[1,5,8,10]$ whereas in others moderate sedation is used. Also support in navigation to the lesion differs (virtual bronchoscopy, fluoroscopy, use of a curette, electromagnetic navigation). Another important issue is the additional analysis of cytology sampled by brush or suction catheter, even when the lesion was not reached with the EBUS-probe.

The aim of this study was to investigate the diagnostic yield of EBUS guided TBB of peripheral pulmonary lesions by flexible bronchoscopy in routine practice applying a moderate sedation protocol. In addition, factors affecting the diagnostic yield and limitations of this method were analyzed.

\section{Methods}

\section{Patient population}

Overall, 257 patients (179 male, 78 female, mean age $68 \pm 12$ years) with peripheral pulmonary lesions diagnosed from January 2006 to September 2008 were investigated. Patients were examined either as outpatients $(n=86,33 \%)$ or during their hospital stay $(n=171,67 \%)$. Data were retrieved retrospectively in a computer database; therefore, informed consent was not mandatory.

\section{Lesions}

Most lesions were solid peripheral lesions. In addition, 18 (7\%) infiltrative lesions were included. The mean diameter was 31.5 $\pm 15.3 \mathrm{~mm}$.

\section{Bronchoscopy}

All patients were investigated by flexible bronchoscopy. The standardized examination included a) a CT scan of the lung prior to bronchoscopy; b) a sedation protocol with midazolam and/or propofol; c) an EBUS guided TBB; and d) a chest radiograph one hour after bronchoscopy.

Flexible bronchoscopy was performed in sedation with a mean dosis of $4.5 \pm 1.7 \mathrm{mg}$ midazolam. In $14 \%$ an additional administration of propofol was necessary (mean dose: $66 \pm 33.5 \mathrm{mg}$ ). In no case general anaesthesia was applied.

For most examinations a videobronchoscope with $3 \mathrm{~mm}$ or 2,8 mm working-channel was used (Olympus BF-1-T-180 and BF-1-T 160). If the lesion was not accessible with this bronchoscope (e.g. because of insufficient angulation of the scope to the apical left bronchus (LB1)), bronchoscopes with smaller diameters were used (Olympus BF-P180 or XBF 4 B40).

After a thorough examination of the bronchial mucosa within view and exclusion of endobronchially visible lesions, endobronchial ultrasonography with $20 \mathrm{MHz}$ radial probe within a $2.6 \mathrm{~mm}$ diameter guide sheath was placed into the lesion (a $2.0 \mathrm{~mm}$ guide sheath when the small-diameter-bronchoscopes were used). After localisation of the peripheral lesions the ultrasonographyprobe was withdrawn and a biopsy forceps (disposable biopsy forceps Olympus: FB 231 D/FB 233D) was placed in the lesion using the guide sheath. At least four transbronchial biopsies were taken. The transbronchial biopsies were analysed histologically and by imprint-cytology. If the peripheral lesion was not visualized by EBUS, $\mathrm{x}$-ray-fluoroscopy was used to assist correct placement of the EBUS-probe into the lesion. If the lesion was not reached with EBUS and additional fluoroscopy, the examination was terminated. A typical example of an EBUS-guided TBB is shown in $\bullet$ Fig. 1.

Patients with a nondiagnostic bronchoscopy were investigated by computertomography-guided transcutaneous biopsy or surgery.

\section{Final diagnoses}

Final diagnoses of patients were retrieved from the charts of the patients and classified as malignant or non-malignant. Overall, 25 patients were lost to follow up.

\section{Statistical analysis}

Categorical variables were described by frequencies and percentages and continuous variables by means and standard deviations. Categorical variables were compared with the chi-square
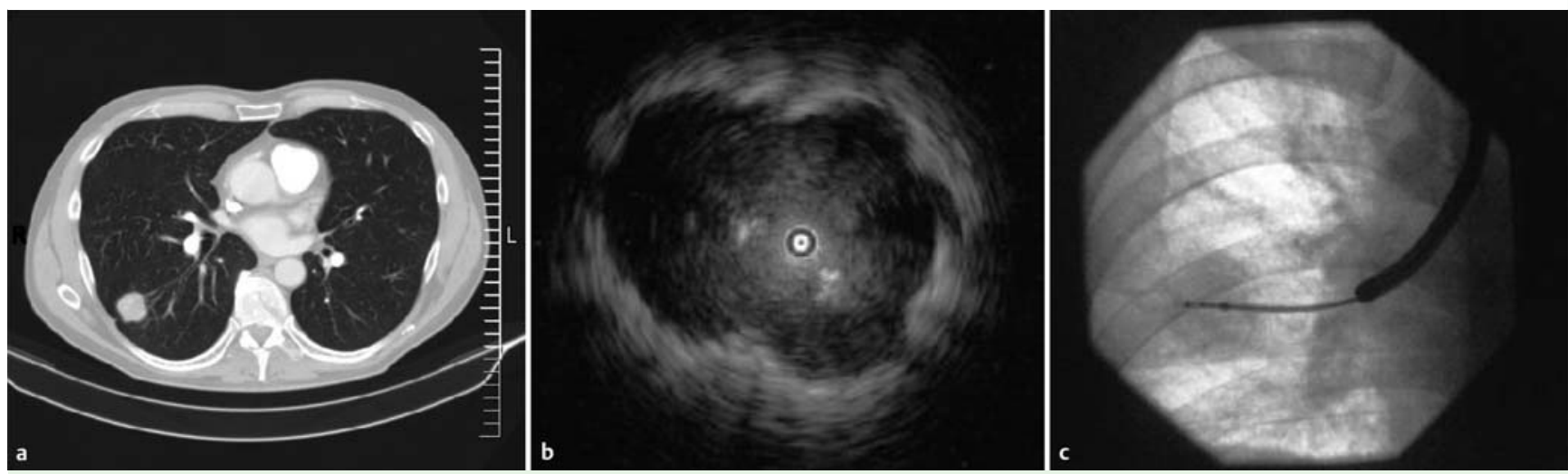

Fig. 1 Typical findings in a computertomography, $\mathbf{b}$ EBUS and $\mathbf{c}$ fluoroscopy during TBB of a peripheral pulmonary lesion in right basal lobe (S10). 
Table 1 Final diagnoses of $\mathrm{n}=257$ patients investigated.

\begin{tabular}{|lrr|}
\hline Diagnoses & \multicolumn{1}{c}{$\mathbf{n}$} & \multicolumn{1}{c|}{$\%$} \\
\hline Malignant diagnoses & 163 & 63.4 \\
\hline SCLC & 17 & 6.6 \\
NSCLC & 121 & 47.1 \\
Metastases of nonpulmonary tumours & 20 & 7.8 \\
Lymphoma & 5 & 1.9 \\
\hline Non-malignant diagnoses & 69 & 26.8 \\
\hline Noninfectious inflammatory lesions & 19 & 7.4 \\
Infectious and postinfectious lesions & 34 & 13.2 \\
Lung fibrosis & 9 & 3.5 \\
Benign tumor & 4 & 1.6 \\
Pulmonary infarction & 3 & 1.2 \\
\hline Lost to follow- up & 25 & 9.7
\end{tabular}

test. Continuous variables were compared using the Student's ttest once normality was demonstrated.

All tests were two-tailed and significance was set at $5 \%$. All analyses were performed with SPSS version 16.0 for Windows (SPSS Inc., Chicago, Illinois, USA).

\section{Results}

$\nabla$

\section{Final diagnoses}

A final diagnosis could be established in 232 patients (90.3\%). In 163 cases $(63.4 \%$ of all, $70.3 \%$ of those with a diagnosis established), the final diagnosis was a malignancy. In this group, nonsmall cell lung cancer was the most frequent diagnosis. In 69 cases, (26.8\% of all, $29.7 \%$ of those with a diagnosis established) a non-malignant diagnosis was made $(\bullet$ Table 1$)$.

\section{Detection of lesions}

In 175 of 257 patients (68.1\%), lesions could be visualized by EBUS. Of these 175 lesions, 33 (18.9\%) were imaged tangentially only. The overall investigation time in visualized lesions was 5.2 $\min \pm 3.7 \mathrm{~min}$. In 136 (77.3\%) cases, $\mathrm{x}$-ray-fluoroscopy was used additionally. The mean fluoroscopy-time was $16.9 \pm 24.2 \mathrm{~s}$.

\section{Diagnostic yield}

Overall, the diagnostic yield of EBUS-TBB was 139 of 257 patients (54.1\%). Of those with EBUS-detected lesions and transbronchial biopsies, the diagnosis could be established in 139 of 175 (79.4\%) patients. In 17 of 175 transbronchial biopsies (9.7\%), diagnosis was exclusively made by the imprint-cytology.

The diagnostic yield depended on the size of the lesion. Both the detection-rate with EBUS and a diagnostic TBB were related to the size of the lesion ( Table 2 ).
The EBUS detection rate depended on the size of the lesions (39.7\% of lesions $\leq 20 \mathrm{~mm}$ vs. $75.6 \%$ of lesions $>20 \mathrm{~mm} / \leq 30 \mathrm{~mm}$ vs. $84.55 \%$ of lesions $>30 \mathrm{~mm})(\mathrm{p}<0.0001)$.

The yield of TBB in patients with a lesion localized with EBUS was $61.3 \%, 85.5 \%$, and $81.7 \%$ in lesions $\leq 20 \mathrm{~mm},>20 \mathrm{~mm} / \leq 30 \mathrm{~mm}$ and $>30 \mathrm{~mm}$, respectively $(\mathrm{p}<0.0001)$.

The overall diagnostic yield was $24.4 \%, 64.6 \%$ and $69.1 \%$ in lesions $\leq 20 \mathrm{~mm},>20 \mathrm{~mm} / \leq 30 \mathrm{~mm}$ and $>30 \mathrm{~mm}$, respectively ( $\mathrm{p}$ $<0.0001)$.

\section{Factors affecting the diagnostic yield}

The EBUS detection-rate in infiltrative lesions was higher than in solid lesions (94.4\% vs. $68.5 \%, \mathrm{p}=0.01$ ). However, the diagnostic yield of TBB was almost equal in infiltrative or solid lesions (82.4\% vs. $77.6 \%$ ).

The positioning of the EBUS-probe was another parameter affecting the diagnostic yield of TBB. If the lesion was reached just tangentially, the yield of TBB was $57.6 \%$ as opposed to $84.5 \%$ if reached centrally $(p=0.01)$.

The diagnostic yield was independent of EBUS-experience of the operator. The diagnostic success of very experienced operators (experience of many years and hundreds of EBUS-TBB-examinations) and less EBUS-experienced operators (more than 20 EBUSexaminations) was equal $(\bullet$ Table $\mathbf{1})$.

\section{Examination times}

The mean EBUS-time from first introduction of EBUS-probe up to termination of the EBUS-examination was $5.23 \mathrm{~min} \pm 3.7 \mathrm{~min}$. The EBUS-time for very experienced operators was shorter than EBUS-time for less experienced operators ( $4.9 \pm 3.5$ vs. $6.2 \pm 4.2$ $\min , \mathrm{p}=0.042$ ).

\section{Complications}

Relevant complications were rare. Postinterventional pneumothoraces occurred in 5 cases (1.9\%). Three pneumothoraces resolved with oxygen-therapy. In two cases, insertion of a chest drain was necessary. Relevant bleeding requiring further intervention like instillation of noradrenaline occurred in two cases. Bleeding was terminated just with holding the guiding sheath in position after TBB or instillation of arterenol. Coughing affecting the progress of examination occurred in 22 cases (8.5\%).

\section{Discussion}

The main findings of our study are the following: 1) in an unselected population with malignancy in $70 \%$ of those with a diagnosis established, flexible bronchoscopy with EBUS guided TBB had a high diagnostic yield (54.1\% overall, $79.4 \%$ if detected by EBUS);

Table 2 Diagnostic yield of EBUS guided EBB and factors affecting the yield.

\begin{tabular}{|c|c|c|c|c|c|c|}
\hline \multirow[b]{2}{*}{ All } & \multicolumn{2}{|c|}{ Lesions detected with EBUS } & \multicolumn{2}{|c|}{ TBB diagnostic } & \multicolumn{2}{|c|}{ Diagnostic yield } \\
\hline & $175 / 257$ & $68,1 \%$ & $139 / 175$ & $79.4 \%$ & $139 / 257$ & $54.1 \%$ \\
\hline$>30 \mathrm{~mm}$ & $82 / 97$ & $84.5 \%$ & $67 / 82$ & $81.2 \%$ & $67 / 97$ & $69.1 \%$ \\
\hline$>20 \mathrm{~mm}, \leq 30 \mathrm{~mm}$ & $62 / 82$ & $75.6 \%$ & $53 / 62$ & $85.5 \%$ & $53 / 82$ & $64,6 \%$ \\
\hline$\leq 20 \mathrm{~mm}$ & $31 / 78$ & $39.7 \%$ & $19 / 31$ & $61.3 \%$ & $19 / 78$ & $24.4 \%$ \\
\hline operator with less EBUS-experience & $46 / 65$ & $70.8 \%$ & $34 / 46$ & $73.9 \%$ & $34 / 65$ & $52.3 \%$ \\
\hline tangential lesion detection & & & $19 / 33$ & $57.6 \%$ & & \\
\hline central lesion detection & & & $120 / 142$ & $84.5 \%$ & & \\
\hline infiltrative lesion & $17 / 18$ & $94.4 \%$ & $14 / 17$ & $82.4 \%$ & $14 / 18$ & $77.8 \%$ \\
\hline
\end{tabular}


2) the diagnostic yield was strongly dependent on the lesion size, with $20 \mathrm{~mm}$ as threshold; 3 ) an additional factor affecting the diagnostic yield was the positioning of the EBUS-probe in the lesion (centrally/tangentially); 4) experience of the operator did not affect the diagnostic yield but determined the duration of the procedure; 5) complications were very rare.

Up to now, 13 studies have been published evaluating EBUSguided TBB, including 8 prospective studies. Only four of these studies included more than 100 patients, and 8 studies (61.5\%) were contributed by two groups from Germany $[1,5,8,10]$ and Japan $[2,4,7,11]$ ( Table 3 ). In addition, a systematic review and meta-analysis has been published recently [12].

The EBUS-detection rate was reported in 11 studies and ranged between 67 and 95\% [1 - 5, 7,9-11,13,14]. The overall diagnostic yield was generally high. A threshold-dependent analysis of the diagnostic yield was provided in 10 studies. Only three report a threshold of $20 \mathrm{~mm}$ determining significant differences in the diagnostic yield $[3,9,11]$. Others found no remarkable threshold [1, $5,8]$, a higher threshold of $30 \mathrm{~mm} \mathrm{[2,7]} \mathrm{or} \mathrm{a} \mathrm{lower} \mathrm{of} 15 \mathrm{~mm} \mathrm{[14].}$ These results are only in part comparable to ours due to a wide variation in study protocols, methodology, and patient populations studied. Of note, only few studies were performed using flexible bronchsocopy only $[3,9]$. Two studies used additional techniques to detect peripheral lesions such as virtual bronchoscopy and bronchoscopic navigation $[8,11]$.

Our observational data are characterized by the following: 1) they were generated in routine practice in a large specialized department of pulmonary medicine; 2) only flexible bronchoscopy was performed; 3 ) they represent the largest series of patients investigated by EBUS-guided TBB. Compared to previous series, the overall diagnostic yield in an unselected population of $54.1 \%$ is moderate but generally in line with others reporting overall yields of 53 to $80 \%$. Clearly, the yield of lesions detected by EBUS-guided TBB depends on the size of the lesion. Remarkable variations in diagnostic yields in lesions $<20 \mathrm{~mm}$ have been reported, some clearly lower than ours (57\% compared to $18 \%-$ $46 \%[7,9,10,11]$, some comparable $(53-55 \%[3,4]$, some clearly higher $(71-76 \%,[2,6,8,14]$. For lesions $\geq 20 \mathrm{~mm}$, most groups report yields of 57 to $80-90 \%[2-4,6,9,11,14]$. Our TBB yield of $79.4 \%$ is in the upper range of these numbers.

Several reasons may account for these differences which apparently are higher in small lesions: 1) two groups identified the position of the probe within or adjacent to the lesion as independent predictors of the diagnostic yield in multivariate analysis $[13,14]$. This finding is confirmed by our data showing a difference in the yield of $84.5 \%$ for centrally versus $57.6 \%$ for tangentially detected versions; 2 ) one group identified the position of the lesion in CT scan as additional independent predictive factor [13]. This appears plausible in view of several bronchial areas difficult to reach with bronchoscopy, however, we were not able to investigate CT scans retrospectively; 3 ) the number of biopsies taken was reported to affect the yield, with five biopsies necessary to achieve the optimal yield [14]. We took at least four biopsies, suggesting that the fifth may not be mandatory in every case. However, we cannot provide a formal analysis about the optimal number of biopsies to be retrieved; 4 ) the lower limit of lesions used to investigate patients with EBUS-guided TBB has not been defined. As such, $<20 \mathrm{~mm}$ may therefore mean at least 10 $\mathrm{mm}$ or even less. Only two studies have formally evaluated the diagnostic yield of EBUS-guided TBB in lesions $<15 \mathrm{~mm}$ and $<10$ $\mathrm{mm}$, resulting in yields of $40 \%$ and $76 \%$, respectively [2,14]. Even so, it is largely up to the decision of the investigator to exclude small lesions in areas difficult to reach with the bronchoscope. Other potential factors cannot be related to different yields. Fluoroscopy was used additionally in three quarters of cases, however, fluoroscopy times were generally very short. With increasing experience, we felt fluoroscopy increasingly dispensable. In fact, studies evaluating EBUS-guided TBB without fluoroscopy found comparable yields $[3,10]$. An exceptionally EBUS-experienced operator obviously does not necessarily produce better results, but his examination times are shorter [14]. This is plausible, since the method is very easy to apply. In addition the ultrasound image of a lesion is instantly recognizable as opposed to the intricate ultrasound patterns of central peribronchial structures. The learning curve for EBUS-guided TBBs is extremely steep. In our series, all operators had several years experience in bronchoscopy and in all examinations a very experienced EBUSoperator was present for purposes of teaching. The prevalence of malignancy was identified as a possible confounder in a recent meta-analysis [12]; however, underlying disease was not found predictive in a multivariate analysis [13]. Finally, lobar distribution and presence of complications were not predictive $[13,14]$. In a recent systematic review and meta-analysis including 16 studies, the reported diagnostic potential for the detection of lung cancer was addressed. EBUS-guided TBB had a point specificity of $1.00(95 \% \mathrm{CI} 0.99-1.00)$ and point sensitivity of 0.73 (95\% CI $0.70-0.76)$, with a positive likelihood ratio of 26.84 (12.60$57.20)$ and a negative likelihood ratio of $0.28(0.23-0.36)$ [12]. While the diagnostic yield achieved is already impressive, there may be room for improvement. Two approaches may be useful in this regard. First, to navigate EBUS-probe to the lesion some operators use a "curette" to change direction under fluoroscopy. This method increases examination-time considerably because there is no direct view on the bronchial structures and the navigation results in a kind of "trial and error". In fluoroscopically invisible lesion this method is not practical. A new navigation-tool is the electromagnetic navigation (EN). This method even allows navigation also to a fluoroscopically invisible lesion. In combination with EBUS to verify location of the probe in the lesion, the diagnostic yield in lesions $<20 \mathrm{~mm}$ can be increased [8]. However, this approach implies increased costs and prolonged examination time with deeper sedation or even need of general anaesthesia. The same is true for a recently described bronchoscope insertion guidance system [15].

Second, in order to optimize the diagnostic success in several studies cytology sampled by brush or suction catheter was used additional to TBB, or without TBB when lesion was not reached. This method increases the diagnostic yield about $10-20 \%$, although several authors do not report how many diagnoses just rely on cytology without reaching the lesion with EBUS. Especially in lesions $<20 \mathrm{~mm}$ with lower detection rates the waiver of this additional diagnostic tool may explain lower diagnostic success in this study. However, the diagnostic validity of cytological diagnosis compared with histological diagnosis is not completely clear. Newer studies using EBUS-TBB without another navigation-tool and without cytology show an even lower diagnostic yield over all in lesions $<20 \mathrm{~mm}$ of $46 \%$ [10]. EBUS-guided TBNA was recently shown to increase the diagnostic yield from $60.6 \%$ for EBUS-guided TBB versus $78.4 \%$ for this procedure plus EBUSguided TBNA [16]. 
Table 3 Overview of reports evaluating EBUS-guided TBNA

\begin{tabular}{|c|c|c|c|c|c|c|c|}
\hline Author/year & Study design & Technique & Patients & Size & $\begin{array}{l}\text { EBUS detec- } \\
\text { tion-rate }\end{array}$ & $\begin{array}{l}\text { Diagnostic } \\
\text { yield over all }\end{array}$ & $\begin{array}{l}\text { Pneumo- } \\
\text { thorax }\end{array}$ \\
\hline Eberhardt R, 2009 & $\begin{array}{l}\text { prospective } \\
\text { case series }\end{array}$ & EBUS & 100 & $\leq 20 \mathrm{~mm}$ & $67 \%$ & $46 \%$ & $3 \%$ \\
\hline Huang CT, 2009 & retrospective & EBUS & 83 & & $72 \%$ & $53 \%$ & \\
\hline Yamada, 2007 & retrospective & $\begin{array}{l}\text { EBUS } \\
\text { fluoroscopy+ } \\
\text { curette }\end{array}$ & 155 & $\begin{array}{l}<15 \mathrm{~mm} \\
15-20 \mathrm{~mm} \\
20-25 \mathrm{~mm} \\
25-30 \mathrm{~mm}\end{array}$ & $85 \%$ & $\begin{array}{l}67 \% \\
40 \% \\
74 \% \\
72 \% \\
81 \%\end{array}$ & \\
\hline Eberhardt R, 2007 & $\begin{array}{l}\text { prospective } \\
\text { rand. cont. trial }\end{array}$ & EBUS & 39 & $\begin{array}{l}<20 \mathrm{~mm} \\
20-30 \mathrm{~mm} \\
>30 \mathrm{~mm}\end{array}$ & & $\begin{array}{l}69 \% \\
78 \% \\
70 \% \\
57 \%\end{array}$ & $5 \%$ \\
\hline & & EN & 39 & $\begin{array}{l}<20 \mathrm{~mm} \\
20-30 \mathrm{~mm} \\
>30 \mathrm{~mm}\end{array}$ & & $\begin{array}{l}59 \% \\
75 \% \\
50 \% \\
69 \%\end{array}$ & $5 \%$ \\
\hline & & $\mathrm{EBUS}+\mathrm{EN}$ & 40 & $\begin{array}{l}<20 \mathrm{~mm} \\
20-30 \mathrm{~mm} \\
>30 \mathrm{~mm}\end{array}$ & & $\begin{array}{l}88 \% \\
90 \% \\
88 \% \\
83 \%\end{array}$ & $8 \%$ \\
\hline Yoshikawa, 2007 & $\begin{array}{l}\text { prospective } \\
\text { case series }\end{array}$ & EBUS & 76 & $\begin{array}{l}>30 \mathrm{~mm} \\
20-30 \mathrm{~mm} \\
<20 \mathrm{~mm}\end{array}$ & & $\begin{array}{l}62 \% \\
90 \% \\
58 \% \\
30 \%\end{array}$ & \\
\hline & & $\begin{array}{l}\text { all bronchosc. } \\
\text { procedures; } \\
\text { EBUS + fluoroscopy } \\
\text { + curette }\end{array}$ & 121 & $\begin{array}{l}>30 \mathrm{~mm} \\
20-30 \mathrm{~mm} \\
<20 \mathrm{~mm}\end{array}$ & $76 \%$ & $\begin{array}{l}86 \% \\
98 \% \\
82 \% \\
76 \%\end{array}$ & $0.8 \%$ \\
\hline Dooms C, 2007 & $\begin{array}{l}\text { prospective } \\
\text { case series }\end{array}$ & $\begin{array}{l}\text { EBUS } \\
\text { no fluoroscopy }\end{array}$ & 50 & $\begin{array}{l}>20 \mathrm{~mm} \\
<20 \mathrm{~mm}\end{array}$ & $74 \%$ & $\begin{array}{l}68 \% \\
82 \% \\
18 \%\end{array}$ & \\
\hline Herth F, 2006 & $\begin{array}{l}\text { prospective } \\
\text { case series }\end{array}$ & EBUS & 54 & & $89 \%$ & $70 \%$ & $1.9 \%$ \\
\hline Paone G, 2005 & $\begin{array}{l}\text { prospective } \\
\text { rand. cont. trial }\end{array}$ & $\begin{array}{l}\text { EBUS } \\
\text { no fluoroscopy }\end{array}$ & 87 & $\begin{array}{l}>30 \mathrm{~mm} \\
<30 \mathrm{~mm} \\
<20 \mathrm{~mm}\end{array}$ & & $\begin{array}{l}79 \% \\
83 \% \\
75 \% \\
71 \%\end{array}$ & \\
\hline Asahina, 2005 & pilot + study & $\begin{array}{l}\text { EBUS + } \\
\text { virt. bronchosc. } \\
\text { fluoroscopy }+ \\
\text { curette }\end{array}$ & 30 & $\begin{array}{l}20-30 \mathrm{~mm} \\
<20 \mathrm{~mm}\end{array}$ & $80 \%$ & $\begin{array}{l}63 \% \\
92 \% \\
44 \%\end{array}$ & $0 \%$ \\
\hline Kurimoto, 2004 & prospective & $\begin{array}{l}\text { EBUS } \\
\text { fluoroscopy }+ \\
\text { curette }\end{array}$ & $\begin{array}{r}150 \\
21 \\
25 \\
35 \\
43 \\
26\end{array}$ & $\begin{array}{l}<10 \mathrm{~mm} \\
10-15 \mathrm{~mm} \\
15-20 \mathrm{~mm} \\
20-30 \mathrm{~mm} \\
>30 \mathrm{~mm}\end{array}$ & $95 \%$ & $\begin{array}{l}77 \% \\
76 \% \\
76 \% \\
69 \% \\
77 \% \\
92 \%\end{array}$ & \\
\hline Yang, 2004 & retrospective & $\begin{array}{l}\text { EBUS } \\
\text { no fluoroscopy }\end{array}$ & 122 & $\begin{array}{l}>20 \mathrm{~mm} \\
<20 \mathrm{~mm}\end{array}$ & $93 \%$ & $\begin{array}{l}66 \% \\
66 \% \\
55 \%\end{array}$ & \\
\hline Kikuchi, 2004 & & $\begin{array}{l}\text { EBUS } \\
\text { fluoroscopy + } \\
\text { curette }\end{array}$ & 24 & $\begin{array}{l}<20 \mathrm{~mm} \\
>20-30 \mathrm{~mm}\end{array}$ & $\begin{array}{r}79 \% \\
67 \% \\
100 \%\end{array}$ & $\begin{array}{l}58 \% \\
53 \% \\
67 \%\end{array}$ & $4.2 \%$ \\
\hline Herth, 2002 & $\begin{array}{l}\text { prospective } \\
\text { case series }\end{array}$ & EBUS & 50 & $\begin{array}{l}>30 \mathrm{~mm} \\
<30 \mathrm{~mm}\end{array}$ & $92 \%$ & $\begin{array}{l}80 \% \\
79 \% \\
80 \%\end{array}$ & $2 \%$ \\
\hline
\end{tabular}


Although applying EBUS after measuring and applying the distance between the orifice of the bronchus and the lesion has been reported to increase the yield of EBUS-guided TBB, the yield achieved (79.9\% versus $57.1 \%$ ) apparently was not considerably higher than the yield reported by most of groups including that of the present study [17].

The strength of our study is the large number of unselected patients included compared with previous EBUS-studies in a real life setting. Moreover, we used exclusively flexible bronchoscopy obviating the need for general anesthesia and included a considerable amount of outpatients. The complication rate was exceedingly low, comparing favourably to previous reports [4,8], proving the feasibility of this diagnostic technique in daily practice. Although the study-design was retrospective, data of EBUS-examinations of peripheral pulmonary lesions were collected for internal quality-control. This clearly improves the confidence in these data.

In conclusion, EBUS-guided TBB of peripheral pulmonary lesions is a safe and successful method which can be established with moderate sedation and within a short examination-time also in outpatients. Under these conditions, the diagnostic yield of EBUS-detected TBB is high, limited only in peripheral lesions $\leq 20 \mathrm{~mm}$.

\section{Conflict of interest}

\section{$\nabla$}

The authors have no conflict of interest.

\section{References}

1 Herth FJ, Ernst A, Becker HD. Endobronchial ultrasound-guided transbronchial lung biopsy in solitary pulmonary nodules and peripheral lesions. Eur Respir J 2002; 20: 972 -974

2 Kurimoto N, Miyazawa T, Okimasa S et al. Endobronchial ultrasonography using a guide sheath increases the ability to diagnose peripheral pulmonary lesions endoscopically. Chest 2004; 126: 959-965

3 Yang MC, Liu WT, Wang CH et al. Diagnostic value of endobronchial ultrasound-guided transbronchial lung biopsy in peripheral lung cancers. J Formos Med Assoc 2004; 103: 124-129
4 Kikuchi E, Yamazaki K, Sukoh $N$ et al. Endobronchial ultrasonography with guide-sheath for peripheral pulmonary lesions. Eur Respir J 2004; 24: 533-537

5 Herth FJ, Eberhardt R, Becker HD et al. Endobronchial ultrasound-guided transbronchial lung biopsy in fluoroscopically invisible solitary pulmonary nodules: a prospective trial. Chest 2006; 129: 147-150

6 Paone G, Nicastri E, Lucantoni G et al. Endobronchial ultrasound-driven biopsy in the diagnosis of peripheral lung lesions. Chest 2005; 128 : $3551-3557$

7 Yoshikawa M, Sukoh N, Yamazaki Ket al. Diagnostic value of endobronchial ultrasonography with a guide sheath for peripheral pulmonary lesions without X-ray fluoroscopy. Chest 2007; 131: 1788-1793

8 Eberhardt R, Anantham D, Ernst A et al. Multimodality bronchoscopic diagnosis of peripheral lung lesions: a randomized controlled trial. Am J Respir Crit Care Med 2007; 176: 36-41

9 Dooms CA, Verbeken EK, Becker HD et al. Endobronchial ultrasonography in bronchoscopic occult pulmonary lesions. J Thorac Oncol 2007; 2: $121-124$

10 Eberhardt R, Ernst A, Herth FJ. Ultrasound-guided transbronchial biopsy of solitary pulmonary nodules less than $20 \mathrm{~mm}$. Eur Respir J 2009; 34: $1284-1287$

11 Asahina H, Yamazaki K, Onodera $Y$ et al. Transbronchial biopsy using endobronchial ultrasonography with a guide sheath and virtual bronchoscopic navigation. Chest 2005; 128: 1761 - 1765

12 Steinfort DP, Khor YH, Manser RL et al. Radial probe endobronchial ultrasound for the diagnosis of peripheral lung cancer: systematic review and meta-analysis. Eur Respir J 2010: [Epub ahead of print]

13 Huang CT, Ho CC, Tsai YJ et al. Factors influencing visibility and diagnostic yield of transbronchial biopsy using endobronchial ultrasound in peripheral pulmonary lesions. Respirology 2009; 14: 859-864

14 Yamada N, Yamazaki K, Kurimoto $N$ et al. Factors related to diagnostic yield of transbronchial biopsy using endobronchial ultrasonography with a guide sheath in small peripheral pulmonary lesions. Chest 2007; 132: 603-608

15 Asano F, Matsuno Y, Tsuzuku A et al. Diagnosis of peripheral pulmonary lesions using a bronchoscope insertion guidance system combined with endobronchial ultrasonography with a guide sheath. Lung Cancer 2008; 60: 366-373

16 Chao TY, Chien MT, Lie CH et al. Endobronchial ultrasonography-guided transbronchial needle aspiration increases the diagnostic yield of peripheral pulmonary lesions: a randomized trial. Chest 2009; 136: 229-236

17 Chung YH, Lie CH, Chao TY et al. Endobronchial ultrasonography with distance for peripheral pulmonary lesions. Respir Med 2007; 101: $738-745$ 